\title{
Interprofessional Education in U.S. Dental Hygiene Programs: A National Survey
}

\author{
Danielle Furgeson, RDH, DHSc, MS; Janet S. Kinney, RDH, MS; Anne E. Gwozdek, RDH, \\ MA; Rebecca Wilder, RDH, MS; Marita R. Inglehart, Dr phil habil
}

Abstract: Although there are many benefits of interprofessional health care, no previous research has sought to define the status of interprofessional education (IPE) in U.S. dental hygiene programs. The aims of this study were to assess how these programs engage in IPE, the challenges they encounter, and the value they place on IPE. Additionally, the study explored how program characteristics are related to IPE. Data were collected with a web-based survey sent to all 322 U.S. dental hygiene program directors (response rate: $33 \%$ of the 305 successfully contacted). The majority of the responding programs were located at institutions with nursing $(90 \%)$ and other allied health programs $(85 \%)$. They were likely to collaborate with nursing $(50 \%)$, other allied health (44\%), and dental assisting programs (41\%), but were less likely to collaborate with dental schools (28\%). IPE was most likely to occur in volunteer activities $(68 \%)$, basic science courses $(65 \%)$, and communication training/behavioral science courses $(63 \% / 59 \%)$. The most frequently reported challenges for IPE were schedule coordination (92\%) and curriculum overload (76\%). The majority of the respondents agreed that IPE was a priority for the dental hygiene profession in the U.S. (59\%) and for the program directors personally (56\%). Programs granting bachelor degrees were more likely to have IPE as a priority than programs that did not grant such degrees (scale of $1-5$ with $5=$ most important: 3.81 vs. $2.88 ; \mathrm{p}<0.01$ ). The longer the students spent in the programs, the more those programs engaged in IPE $(r=0.21 ; \mathrm{p}<0.05)$. The data collected in this study can contribute to future efforts to help dental hygiene programs engage in meaningful IPE and contribute to developing interprofessional care in the U.S. health care system.

\begin{abstract}
Dr. Furgeson is Clinical Assistant Professor, Department of Periodontics and Oral Medicine, School of Dentistry, University of Michigan; Prof. Kinney is Director, Dental Hygiene Program and Clinical Associate Professor, Department of Periodontics and Oral Medicine, School of Dentistry, University of Michigan; Prof. Gwozdek is Director, Dental Hygiene Graduate and Degree Completion Programs, and Clinical Assistant Professor, Department of Periodontics and Oral Medicine, School of Dentistry, University of Michigan; Prof. Wilder is Professor, Director of Faculty Development, and Director of Graduate Dental Hygiene Education, Department of Dental Ecology, School of Dentistry, University of North Carolina at Chapel Hill; and Dr. Inglehart is Professor, Department of Periodontics and Oral Medicine, School of Dentistry and Adjunct Professor, Department of Psychology, College of Literature, Science, and Arts, University of Michigan. Direct correspondence to Dr. Danielle Furgeson, Department of Periodontics and Oral Medicine, University of Michigan School of Dentistry, 1011 N. University Avenue, Ann Arbor, MI 48109-1078; 734-764-0033; furgeson@umich.edu.
\end{abstract}

Keywords: dental hygiene, dental hygiene education, interprofessional relations, interprofessional education, interdisciplinary communication, dental hygiene programs

Submitted for publication 1/28/15; accepted 4/4/15

I n 2010, the World Health Organization published its Framework for Action on Interprofessional Education and Collaborative Practice, which stressed the importance of interprofessional collaboration (IPC) for providing better health care services, which would ultimately improve health outcomes. ${ }^{1}$ In 2012, Formicola et al. reported the findings of the American Dental Education Association (ADEA) Team Study Group on Interprofessional Education regarding the status of interprofessional education (IPE) in dental schools in the U.S. and Canada. ${ }^{2}$ This group reviewed the relevant IPE literature, examined the Commission on Dental Accreditation (CODA) standards concerning IPE, ${ }^{3}$ surveyed U.S. and Canadian dental schools to determine their current and planned IPE activities, and described the best practices of six exemplary IPE programs in dental schools. Based on the survey, which had an $86 \%$ response rate, the group concluded that North American dental schools recognized the importance of IPE but differed widely in their efforts to incorporate IPE into their educational efforts.

Although no previous research has assessed the status of IPE in U.S. dental hygiene programs, this situation deserves attention because dental hygienists practice in close collaboration with dentists and additional IPC seems to be a logical next step., ${ }^{4,5}$ Anderson et al. reported, for example, that dental 
hygiene educators and their programs are well placed to collaborate with other allied health professions, such as nursing and physician assistants, to include oral health in the primary care setting. ${ }^{6}$ In addition, dental hygienists have increasingly more opportunities for IPC in community centers and other health care institutions due to changes in licensure. ${ }^{7}$ Forming IPE partnerships has been found to help build opportunities to become part of IPC teams. These partnerships have been identified as one way to contribute to a paradigm shift in dental and dental hygiene education. ${ }^{8}$

Dental hygiene is well placed to be a key player in IPE. While IPE is not explicitly mentioned in the accreditation standards for dental hygiene education, these standards require graduates to be competent in communicating with other health care providers. ${ }^{9}$ Specifically, Standard 2-15 requires graduates to be competent in both interpersonal and communication skills for collaboration with other health care disciplines for comprehensive patient care. Other standards such as 2-13a and 2-13f require the collection of all necessary patient health information, which often requires collaboration with other health care providers, and competence in problem-solving strategies related to comprehensive patient care. Additionally, dental hygiene practice is being incorporated into more nontraditional settings such as long-term care facilities, hospitals, and public health venues. Therefore, the dental hygiene curriculum must include IPE experiences that will prepare students to serve in those situations that call for IPC. ${ }^{8}$

A question of interest is in which specific IPE collaborations dental hygiene programs are currently engaged. The study of IPE efforts in dental schools addressed this question by first asking respondents to indicate which allied health programs were present at their institutions and then with which programs the dental schools actually engaged in IPE efforts. ${ }^{2}$ That study found that $82 \%$ of responding dental schools had a medical and a nursing school on campus; $65 \%$ a pharmacy school, physical therapy program, and psychology department; and only $50 \%$ a dental hygiene program. In response to the question about programs with which they were engaged in IPE, 63\% reported that they collaborated with their medical school and $58 \%$ engaged in IPE with a dental hygiene program. Fewer than half of the schools had IPE activities with other disciplines. The first aim of our study was therefore to collect information about which health professions programs are present in the dental hygiene programs' institutions as well as with which disciplines the programs actively engage in IPE.

In addition, it is critical to understand how IPE is concretely placed in the didactic and clinical context of dental hygiene education. The results from the dental school survey showed that the highest percentage of IPE activities were joint volunteer activities $(66 \%)$, followed by clinical activities $(60 \%)$ and service-learning projects $(52 \%){ }^{2}$ All other IPE activities such as joint basic science courses $(32 \%)$, communication training $(31 \%)$, and ethics courses $(15 \%)$ were reported by fewer than half of the responding dental schools. The second aim of our study was therefore to determine in which tangible IPE experiences dental hygiene programs engage and, specifically, whether these activities are aligned with CODA standards 2-13a, 2-13f, and 2-15, which indirectly refer to IPC. ${ }^{9}$

When designing IPE, careful planning is crucial. ${ }^{10,11}$ For example, establishing a positive interprofessional team environment and developing an appropriate interprofessional team culture should be part of curriculum planning for IPE. ${ }^{11}$ Dental hygiene educators must ensure that any IPE curriculum development is not only workable within dental hygiene, but also within the collaborating disciplines..$^{10-12}$ It is therefore not surprising that establishing IPE faces severe challenges. The dental school IPE survey identified three categories of challenges. ${ }^{2}$ The first category consisted of organizational issues such as finding a location and time in the curriculum; second, person-related challenges were found, such as problems with adequate leadership support and adequately trained faculty; the third category was comprised of cultural and philosophical challenges.

Other studies have found that a lack of support from institutional administration at the dean level was a severe challenge that weakened any IPE initiative. ${ }^{10-12}$ Additional reported barriers to the integration of IPE have been that major curriculum revisions were needed and that faculty buy-in for these changes was necessary. ${ }^{11,12}$ Lack of faculty preparation, IPE understanding, and calibration has also been reported to be a significant barrier to successfully integrating IPE. ${ }^{13}$ One final reported challenge, reported by Ateah et al., relates to the fact that a previous lack of engagement with other disciplines has frequently resulted in misconceptions about other health professions. ${ }^{14}$ These misconceptions can create hierarchies that become difficult barriers to surmount when developing IPE and engaging in IPC in clinical settings. Ateah et al. showed, for example, that dental 
hygienists were perceived to be lacking in academic ability, decision making, and leadership skills and that these negative perceptions had significantly improved after IPE.

Based on these research findings in other disciplines, another aim of our study was to assess the challenges that dental hygiene program directors encounter when implementing IPE, as well as exploring whether certain program characteristics such as program length or type of degree conferred affect the way programs engage in IPE. In summary, the aims of this study were to assess how U.S. dental hygiene programs engage in IPE, what challenges they encounter, the value they place on IPE, and how program characteristics are related to IPE.

\section{Methods}

This study was determined to be exempt from oversight by the Institutional Review Board for the Behavioral and Health Sciences at the University of Michigan (HUM\#00083956). The email addresses of 322 directors of entry-level dental hygiene programs were obtained from the dental hygiene education program page on the American Dental Hygienists' Association (ADHA) website. A first recruitment email was sent in February 2014 to each of the program directors individually. This email informed them about the study and provided a link to an anonymous web-based survey. Two follow-up emails were sent in April and May.

The survey was a revised version of the survey used by the ADEA Team Study Group on Interprofessional Education to investigate IPE activities in U.S. and Canadian dental schools. ${ }^{2}$ Permission to adapt this survey for use with U.S. dental hygiene programs was obtained from Dr. Allan J. Formicola, head of that study group. We made two revisions to the survey. First, we changed the questions concerning the program characteristics to be more genuinely relevant for dental hygiene programs. Second, we replaced the dental accreditation standards with the dental hygiene accreditation standards that were relevant to IPE.

Part I of our survey inquired about dental hygiene program characteristics, including the program's educational setting, degree/s granted, number of annual graduates, and length of time for degree completion. Part II focused on identifying which potential IPE collaborations between dental hygiene programs and other disciplines were pos- sible and which actually existed. Another question asked in which specific IPE activities the programs were engaged such as whether they had joint ethics, basic science, or behavioral science courses. Part III inquired whether IPE activities were related to the dental hygiene CODA standards that have an implied connection with IPE. ${ }^{9}$ Those questions asked which IPE-related activities the programs included in their efforts to demonstrate compliance with the spirit of the relevant standards. In addition, the program directors were asked to describe any plans to include IPE activities to comply with the intent of these standards in the future and to assess the outcomes of their IPE engagement. The last part of the survey asked about challenges encountered by the programs when trying to engage in IPE activities.

The data were downloaded from the website as an Excel file and imported into SPSS (Version 21). Descriptive statistics such as frequencies, percentages, means, standard deviations, and ranges were computed to provide an overview of answers to the closed-ended questions. The answers to the openended questions were transcribed and thematically coded by two of the authors. Step 1 was to determine coding categories for each open-ended question that were mutually exclusive and comprehensive. Step 2 was to group the open-ended responses under these major categories. Coding discrepancies were resolved by discussion until agreement was achieved. The frequencies of responses in each category were then determined. Independent sample t-tests were used to determine if the average responses of programs that offered baccalaureate degrees differed from those that did not. Pearson correlation coefficients were used to determine if there was a relationship between the responses and program length or number of graduates per year. The level of statistical significance was set at $\mathrm{p}=0.05$.

\section{Results}

Of the first emails sent to 322 program directors, 17 were undeliverable, and 56 program directors completed the survey. In April 2014, a first follow-up, individualized email was sent, asking those who had not yet responded to do so. This email resulted in 28 additional responses. On May 8, a second follow-up group email was sent through the ADEA Council on Dental Hygiene Program Directors' listserv. This email informed the recipients that 84 programs had responded and asked nonrespondents for their par- 
ticipation; 18 additional surveys were received in response to this second follow-up email. Ultimately, of the 305 programs successfully contacted, a total of 102 submitted a survey, but some skipped individual questions and one respondent skipped all of Part II. The overall response rate was $33 \%$.

Of the 102 respondents, $49 \%$ were located at a community or junior college, $17 \%$ at a school of allied health sciences, $14 \%$ at a dental school, 13\% at a university or four-year college, and $6 \%$ at a technical college. An associate degree was offered by $79 \%$ of the programs, a baccalaureate degree by $29 \%$, and a diploma or certificate by $3 \%$. The number of students who graduate per year ranged from 10 to 60 (Mean=25; $\mathrm{SD}=10.52$ ). The length of the programs ranged from 18 to 48 months (Mean=26 months; $\mathrm{SD}=6.04$ ).

Table 1 provides an overview of other healthrelated programs at the respondents' institutions. The majority of programs had a nursing school $(90 \%)$, another allied health program $(85 \%)$, and a psychology department (61\%) on their campus. While $41 \%$ had a dental assisting program, only $20 \%$ had a dental school and $18 \%$ a dental specialty graduate program. When asked with which of these programs they collaborated, the most commonly named program was nursing $(50 \%)$, followed by other allied health programs (44\%) and dental assisting programs (41\%). In addition, $28 \%$ collaborated with a dental school, $18 \%$ with a dental specialty program, and $11 \%$ with a medical school. Very few programs collaborated with a psychology department or social work program.

Table 2 provides an overview of joint program activities. The highest percentage of joint efforts involved volunteer activities (68\%), followed by basic science courses $(65 \%)$, communication training $(63 \%)$, and behavioral science courses (59\%). Joint community-based clinical education and service-learning projects occurred in about half of the programs ( $48 \%$ and $50 \%$, respectively), while joint efforts in ethics classes were reported by only $8 \%$ of the respondents.

Three questions concerning IPE-related challenges were included in the survey. The first question asked "How challenging is it for your program to engage in IPE?" Response options were on a five-point scale from $1=$ not at all to $5=$ very challenging. The average response was $3.62(\mathrm{SD}=0.95$; range 2-5), indicating a high level of encountered challenges. Second, the respondents answered the question "Which challenges related to IPE do you currently encounter?" by checking which of the nine
Table 1. Health professions programs at dental hygiene programs' institutions and those with which the programs collaborate for IPE activities, by percentage of total respondents to this part $(n=101)$

\begin{tabular}{lcc} 
Program & $\begin{array}{c}\text { Yes: At } \\
\text { Institution }\end{array}$ & $\begin{array}{c}\text { Yes: Have } \\
\text { Collaboration }\end{array}$ \\
\hline Dental school & $20 \%$ & $28 \%$ \\
Dental specialty graduate program & $18 \%$ & $18 \%$ \\
Dental therapy program & 0 & $2 \%$ \\
Dental assisting program & $41 \%$ & $41 \%$ \\
Medical school & $21 \%$ & $11 \%$ \\
Physician assistant program & $20 \%$ & $8 \%$ \\
Nursing school & $90 \%$ & $50 \%$ \\
Pharmacy program & $25 \%$ & $10 \%$ \\
Physical therapy program & $32 \%$ & $7 \%$ \\
Other allied health program & $85 \%$ & $44 \%$ \\
Psychology department & $61 \%$ & $10 \%$ \\
Social work program & $44 \%$ & $10 \%$ \\
Other: & & \\
$\quad$ Physical therapy assistant & $5 \%$ & $18 \%$ \\
$\quad$ Radiology technician & $10 \%$ & $4 \%$ \\
$\quad$ EMS/EMT/paramedic & $14 \%$ & $8 \%$
\end{tabular}

Note: The percentages of dental hygiene programs that have collaborations were based on those programs that had other health professions programs at their institutions.

Table 2. Activities at dental hygiene programs that allow interactions between students from different disciplines, by percentage of total respondents $(n=102)$

\begin{tabular}{lc} 
Activity & Yes: Have Activity \\
\hline Volunteer activities & $68 \%$ \\
Basic science course & $65 \%$ \\
Communication training & $63 \%$ \\
Behavioral science courses & $59 \%$ \\
Service-learning projects & $50 \%$ \\
Community-based clinical education & $48 \%$ \\
Clinical activities & $43 \%$ \\
Standardized patient programs & $25 \%$ \\
Ethics classes & $8 \%$ \\
\hline
\end{tabular}

listed challenges they had experienced (Table 3). The most frequently checked challenges were schedule coordination (92\%), curriculum overload (76\%), calibration of faculty (48\%), and having meaningful interactions with students $(42 \%)$. Fewer respondents reported that a lack of space $(33 \%)$ and evaluating outcomes $(32 \%)$ were a problem, and very few chose a lack of educational resources (14\%) and support from administration (16\%) as challenges. Third, the open-ended question "Which challenges related to IPE do you expect to encounter in the future?" was asked. Of the 13 responses to this question, six cited 
scheduling issues and logistic problems, three a lack of other programs to collaborate with, and two a lack of administrative support from their institution as challenges.

Table 4 shows the respondents' perspectives on the value of IPE. The program directors were first asked to rate how important IPE is as one of the top five priorities for them personally, for their academic institution, and for the dental hygiene profession in the U.S., using a scale from $1=$ not at all important to $5=$ extremely important. The majority of respondents

Table 3. Challenges related to interprofessional education that dental hygiene programs experience, by percentage of total respondents $(n=102)$

\begin{tabular}{lc} 
Challenge & Yes: Face Challenge \\
\hline Schedule coordination & $92 \%$ \\
Curriculum overload & $76 \%$ \\
Calibrated faculty & $48 \%$ \\
Opportunities for meaningful student & $42 \%$ \\
$\quad$ interactions & $33 \%$ \\
Room space & $32 \%$ \\
Evaluating outcomes & $26 \%$ \\
Partnership opportunities within home & \\
$\quad$ institution & $16 \%$ \\
Support from administration & $14 \%$ \\
Educational resources &
\end{tabular}

indicated that IPE was very (34\%) or extremely important (24\%) for themselves, but fewer thought that it was very $(22 \%)$ or extremely important $(18 \%)$ for their institution. However, the majority responded that IPE was very $(28 \%)$ or extremely important (29\%) for the dental hygiene profession in the U.S. An open-ended question "Please explain your answer choices in the Comments section" followed these three closed-ended questions. Of the 102 program directors, 21 provided an answer. Six respondents thought that IPE is important to universities/colleges/educational programs, and four noted that it was critical for the dental hygiene profession. Three pointed to the importance of communication among health care providers, and two described a need for comprehensive patient care.

In addition, the respondents were asked how important it was that their graduates were competent in the four interprofessional collaboration areas included in the study of dental schools in the U.S. and Canada. ${ }^{2}$ These four competencies were "working with individuals of other professions to maintain a climate of mutual respect and shared values," "using the knowledge of one's own role and those of other professions to appropriately assess and address the health care needs of the patients and populations served," "communicating with patients, families, communities, and other health professionals in a

Table 4. Dental hygiene program directors' perspectives on interprofessional education (IPE) as a priority and graduates' competence, by number and percentage of respondents to each item

\begin{tabular}{|c|c|c|c|c|c|c|}
\hline Priorities/Competence & $\begin{array}{l}1 \\
\text { Not at All } \\
\text { Important }\end{array}$ & 2 & 3 & 4 & $\begin{array}{l}5 \\
\text { Extremely } \\
\text { Important }\end{array}$ & $\begin{array}{l}\text { Mean } \\
\text { SD }\end{array}$ \\
\hline \multicolumn{7}{|l|}{ IPE is one of the top five priorities for: } \\
\hline Me as a dental hygiene program director. $(\mathrm{n}=98)$ & $\begin{array}{c}2 \\
2 \%\end{array}$ & $\begin{array}{c}10 \\
10 \%\end{array}$ & $\begin{array}{c}30 \\
29 \%\end{array}$ & $\begin{array}{c}33 \\
34 \%\end{array}$ & $\begin{array}{c}23 \\
24 \%\end{array}$ & $\begin{array}{l}3.68 \\
1.021\end{array}$ \\
\hline My academic institution. $(\mathrm{n}=96)$ & $\begin{array}{c}8 \\
8 \%\end{array}$ & $\begin{array}{c}25 \\
26 \%\end{array}$ & $\begin{array}{c}25 \\
26 \%\end{array}$ & $\begin{array}{c}21 \\
22 \%\end{array}$ & $\begin{array}{c}17 \\
18 \%\end{array}$ & $\begin{array}{l}3.15 \\
1.231\end{array}$ \\
\hline The dental hygiene profession in the United States. $(n=91)$ & $\begin{array}{c}1 \\
1 \%\end{array}$ & $\begin{array}{l}7 \\
7 \%\end{array}$ & $\begin{array}{c}24 \\
24 \%\end{array}$ & $\begin{array}{c}29 \\
28 \%\end{array}$ & $\begin{array}{c}30 \\
29 \%\end{array}$ & $\begin{array}{l}3.88 \\
0.998\end{array}$ \\
\hline \multicolumn{7}{|l|}{ Graduates must be competent to: } \\
\hline $\begin{array}{l}\text { Work with individuals of other professions to maintain a } \\
\text { climate of mutual respect and shared values. }(n=96)\end{array}$ & 0 & $\begin{array}{c}1 \\
1 \%\end{array}$ & $\begin{array}{c}10 \\
10 \%\end{array}$ & $\begin{array}{c}16 \\
16 \%\end{array}$ & $\begin{array}{c}69 \\
72 \%\end{array}$ & $\begin{array}{r}4.59 \\
0.719\end{array}$ \\
\hline $\begin{array}{l}\text { Use the knowledge of one's own role and those of other } \\
\text { professions to appropriately assess and address the health } \\
\text { care needs of the patients and populations served. }(n=95)\end{array}$ & 0 & $\begin{array}{c}1 \\
1 \%\end{array}$ & $\begin{array}{c}9 \\
10 \%\end{array}$ & $\begin{array}{c}21 \\
22 \%\end{array}$ & $\begin{array}{c}64 \\
67 \%\end{array}$ & $\begin{array}{l}4.56 \\
0.710\end{array}$ \\
\hline $\begin{array}{l}\text { Communicate with patients, families, communities, and } \\
\text { other health professionals in a responsive and responsible } \\
\text { manner that supports a team approach to the maintenance } \\
\text { of health and treatment of disease. }(n=95)\end{array}$ & 0 & $\begin{array}{c}1 \\
1 \%\end{array}$ & $\begin{array}{c}7 \\
7 \%\end{array}$ & $\begin{array}{c}16 \\
17 \%\end{array}$ & $\begin{array}{l}71 \\
75 \%\end{array}$ & $\begin{array}{l}4.65 \\
0.665\end{array}$ \\
\hline $\begin{array}{l}\text { Apply relationship-building values and the principles of } \\
\text { team dynamics to perform effectively in different team } \\
\text { roles to plan and deliver patient-/population-centered care } \\
\text { that is safe, timely, efficient, effective, and equitable. }(\mathrm{n}=96)\end{array}$ & ) & $\begin{array}{c}2 \\
2 \%\end{array}$ & $\begin{array}{c}8 \\
8 \%\end{array}$ & $\begin{array}{c}21 \\
22 \%\end{array}$ & $\begin{array}{c}65 \\
68 \%\end{array}$ & $\begin{array}{c}4.55 \\
0.738\end{array}$ \\
\hline
\end{tabular}


responsive and responsible manner that supports a team approach to the maintenance of health and treatment of disease," and "applying relationshipbuilding values and the principles of team dynamics to perform effectively in different team roles to plan and deliver patient-/population-centered care that is safe, timely, efficient, effective, and equitable." The average responses to these questions indicated an exceptionally high level of perceived importance of these competencies (Table 4).

In addition to providing an overview of the responses, it is also worthwhile to analyze whether program characteristics affected the responses. Table 5 shows the average responses of programs that confer vs. do not confer a baccalaureate degree. The programs with baccalaureate degrees had on average more health programs in their institutions $(6.40$ vs. $4.19 ; \mathrm{p}<0.001)$ and collaborated with more programs $(3.40$ vs. $2.21 ; p=0.005)$ than nonbaccalaureate-granting programs. In addition, the baccalaureate-granting programs reported that IPE was more important for their institutions than the non-baccalaureate-granting programs (on a fivepoint scale with $1=$ lowest importance: 3.81 vs. 2.88 ; $\mathrm{p}=0.001$ ). However, the two sets of programs did not differ in average numbers of IPE activities, IPErelated challenges encountered, or the importance they assigned to IPE regarding CODA standardrelated activities.

The relationships between program length and number of graduates per year and the IPE-related responses were also analyzed. The longer the time to degree completion, the higher the sum of activities $(r=0.21 ; p=0.03)$ and the higher the priority of IPE for their academic institutions $(r=0.34 ; p<0.001)$. The number of graduates per year was correlated with

Table 5. Differences in interprofessional education (IPE)-related responses of programs that grant vs. do not grant a baccalaureate degree and correlations between these responses and program length and number of graduates per year

\begin{tabular}{|c|c|c|c|c|c|}
\hline IPE-Related Responses & $\begin{array}{c}\text { Baccalaureate } \\
\text { Degree: No } \\
\mathrm{N}=72\end{array}$ & $\begin{array}{c}\text { Baccalaureate } \\
\text { Degree: Yes } \\
N=30\end{array}$ & p-value & $\begin{array}{l}\text { Length } \\
\text { of } \\
\text { Program }\end{array}$ & $\begin{array}{c}\text { Number of } \\
\text { Graduates } \\
\text { per Year }\end{array}$ \\
\hline Sum of programs on campus ${ }^{\mathrm{a}}$ & 4.19 & 6.40 & $<0.001$ & 0.19 & $0.28^{* *}$ \\
\hline Sum of programs with which collaborations take place & 2.21 & 3.40 & 0.005 & 0.10 & $0.29^{* *}$ \\
\hline Proportion of programs with collaborations on campus ${ }^{b}$ & 57.71 & 71.68 & 0.277 & 0.01 & 0.11 \\
\hline \multicolumn{6}{|l|}{ Educational activities } \\
\hline Sum of activities ${ }^{c}$ & 4.39 & 4.57 & 0.713 & $0.21 *$ & 0.13 \\
\hline Sum of clinical activities ${ }^{d}$ & 1.97 & 2.37 & 0.208 & 0.15 & 0.05 \\
\hline Sum of classroom-based activities ${ }^{\mathrm{e}}$ & 2.26 & 2.00 & 0.397 & 0.18 & 0.01 \\
\hline \multicolumn{6}{|l|}{ IPE-related challenges } \\
\hline Overall degree of challenge $\mathrm{f}^{\mathrm{f}}$ & 3.66 & 3.54 & 0.582 & -0.11 & 0.00 \\
\hline Sum of challenges ${ }^{g}$ & 3.63 & 4.13 & 0.184 & 0.08 & 0.13 \\
\hline \multicolumn{6}{|l|}{ IPE as priority ${ }^{h}$} \\
\hline For dental hygiene program director & 3.65 & 3.74 & 0.704 & 0.04 & $0.24 *$ \\
\hline For academic institution & 2.88 & 3.81 & 0.001 & $0.34^{* * *}$ & 0.15 \\
\hline For dental hygiene profession & 3.80 & 4.08 & 0.239 & 0.14 & 0.19 \\
\hline \multicolumn{6}{|l|}{ Importance ${ }^{h}$} \\
\hline Competent in other professions & 4.57 & 4.67 & 0.537 & 0.07 & $0.23 *$ \\
\hline Competent in own role & 4.54 & 4.59 & 0.766 & -0.01 & 0.14 \\
\hline Communication with stakeholders & 4.66 & 4.63 & 0.833 & 0.08 & 0.06 \\
\hline Competent in relationship-building & 4.55 & 4.56 & 0.977 & 0.00 & 0.04 \\
\hline \multicolumn{6}{|c|}{$\begin{array}{l}\text { answers ranged from } 0 \text { to } 13 \text { other programs on the dental hygiene programs' campus (see Table } 1 \text { for programs). } \\
\text { bThis index provides the percentage of collaborations based on number of programs available/on campus. } \\
\text { cThis index ranged from } 0 \text { to } 9 \text { joint IPE activities in which programs were engaged (see Table } 2 \text { for activities). } \\
\text { 'This index ranged from } 0 \text { to } 4 \text { joint clinical IPE activities in which programs were engaged. Activities were joint volunteer activities, } \\
\text { service-learning projects, community-based clinical education, and clinical activities. } \\
\text { eThis index ranged from } 0 \text { to } 5 \text { joint classroom-based IPE activities in which programs were engaged. Activities were joint basic science } \\
\text { courses, communication training, behavioral science courses, standardized patient programs, and ethics classes. } \\
\text { 'Overall degree of challenge was assessed with the question "How challenging was it for you to engage in IPE?" Response options } \\
\text { ranged from } 1=\text { not at all to } 5=\text { very challenging. } \\
\text { gThis index ranged from } 0 \text { to } 9 \text { (see Table } 3 \text { for list of challenges). } \\
\text { "Response options ranged from } 1=\text { not at all to } 5=\text { =xtremely important. }\end{array}$} \\
\hline \multicolumn{6}{|l|}{${ }^{*} \mathrm{p}<0.05 ;{ }^{* *} \mathrm{p}<0.01 ;{ }^{* * *} \mathrm{p}<0.001$} \\
\hline
\end{tabular}


the sum of programs on campus $(r=0.28 ; p=0.005)$, the sum of programs with whom they had IPE collaborations $(r=0.29 ; p=0.004)$, the priority of IPE for the program directors $(\mathrm{r}=0.24 ; \mathrm{p}<0.05)$, and how much the directors valued that their students were competent to collaborate with providers from other professions $(r=0.23 ; \mathrm{p}<0.05)$.

\section{Discussion}

The Affordable Care Act accelerated a change in the health care paradigm that affects the provision of health care. The focus is on increased access to care, coordination of care, and connecting patients to needed health resources in their communities in the pursuit of improved health outcomes. ${ }^{15,16}$ This paradigm shift makes interprofessional care integral to providing health care. IPE prepares future care providers for this new situation and helps them to develop a better understanding of their own role and the role of providers from other disciplines. ${ }^{17}$ Curran et al. found that the maximum impact of IPE can be achieved when students are exposed to IPE both early and frequently during the course of their studies. ${ }^{18}$ Given this situation, it is important for educators to develop a better understanding of the status of IPE in U.S. dental hygiene programs.

The first aim of this study was to determine how many other health professions programs were located in the same institutions as dental hygiene programs and with how many of these disciplines the dental hygiene programs had joint IPE activities. A comparison of the results of this study of dental hygiene programs with the findings regarding U.S. and Canadian dental schools ${ }^{2}$ showed that both types of programs were very likely to have a nursing school on their campus ( $90 \%$ vs. $82 \%$ ) and to collaborate with that program ( $50 \%$ vs. $47 \%)$. However, campuses with a dental hygiene program were less likely to have a dental school (20\% vs. $50 \%$ ), medical school ( $21 \%$ vs. $82 \%$ ), pharmacy school ( $25 \%$ vs. $65 \%)$, or physical therapy program $(32 \%$ vs. $65 \%)$ than the dental schools. This finding is likely due to the fact that $49 \%$ of the dental hygiene programs were located at a community or junior college and $6 \%$ at a technical college, which are institutions that do not usually have a dental or medical school. This fact also explains why $58 \%$ of the dental schools reported joint IPE with dental hygiene programs, while only $38 \%$ of the dental hygiene programs reported having joint IPE activities with dental schools.
Concerning the joint IPE activities in which these dental hygiene programs and dental schools engaged, the majority of both types of programs reported joint volunteer activities $(68 \%$ vs. $66 \%)$ and service-learning projects ( $50 \%$ vs. $52 \%$ ). This finding raises the question of whether these types of activities were voluntary and not a required part of the core curricula. Future research should assess in more detail which specific joint activities are required and which are merely self-selected activities that may not provide optimally developed IPE situations. In addition, the majority of responding dental hygiene program directors reported that their programs engaged in joint basic science courses (65\%), communication training (63\%), and behavioral science courses (59\%). Future studies should include an assessment of the quality of joint IPE because it is possible that reports about joint classes do not describe true IPE interactions, but merely side-by-side didactic learning in large classroom settings.

While these dental hygiene program directors reported valuing IPE and viewing it as imperative to dental hygiene practice, they noted many barriers to its implementation. The challenges were reflective of barriers found in other studies as well. ${ }^{10-12,19}$ The most frequently reported challenges were schedule coordination and curriculum overload, two issues that were reported in a previous study. ${ }^{12}$ In addition, the fact that faculty calibration was named as a challenge by about half of the respondents was also consistent with the findings in other studies. ${ }^{11,13}$ Overall, these program directors reported that IPE was viewed positively by their institutions - which may explain why so few reported a lack of institutional support as a challenge. This finding suggests that IPE may now be considered an essential aspect of health professions education.

In addition to exploring barriers and challenges to implementing IPE, these program directors also indicated the degree to which they themselves, their institutions, and the dental hygiene profession in the U.S. considered IPE to be a priority. It is interesting that the respondents perceived IPE to be a priority for the dental hygiene profession and for them personally. However, they ranked it as a priority for their own institutions slightly lower. Specifically, these directors indicated their opinion that interprofessional care related to the CODA standards was very important. For example, the majority of the respondents reported that it was very important for dental hygienists to learn to work with members of other disciplines and utilize the collective knowledge of each stakeholder to provide safe, appropriate, and 
holistic care for patients and the population at large. These underlying values are likely to ensure that IPE will continue to develop in dental hygiene programs. Ultimately, these efforts should contribute to educating other health professionals about the role dental hygienists can play as part of health care teams, thus raising the profile of the relevance of dental hygiene in the contribution of total health care.

This study had several limitations. First, only 102 of the 305 contacted dental hygiene program directors responded. This low response rate may be due to the fact that the survey was distributed during a time in the academic year when programs were preparing their students for national and clinical boards. Future studies should consider conducting the survey at a different time of year. In this study, it cannot be excluded that programs with IPE efforts were more likely than programs without any IPE activities to respond. Generalizations to all U.S. dental hygiene programs should therefore be made cautiously. In addition, the data were collected with a survey that included many rating scale format questions. Asking the program directors to submit concrete lesson plans or syllabi could have provided a more objective basis for assessing the quality of IPE activities. Future research should consider including curriculum analyses together with general survey approaches. Finally, by utilizing the survey that had been developed for assessing IPE in dental schools, some areas of interest were not included. For example, it would be interesting to gain a better understanding of the assessment of outcomes of IPE efforts.

\section{Conclusion}

With the rapidly changing landscape in oral health care in the U.S., IPE is imperative for the health care system at large and for dental hygiene education specifically. The results of this study suggest that dental hygiene programs are situated in academic environments with multiple health profession programs on the same campus. However, at the time of this survey, most programs did not engage in extensive IPE with these potential partners. The majority of the responding programs reported IPE efforts that consisted of either voluntary activities or efforts that may not truly qualify as IPE (for example, having students from different disciplines attend the same basic science lectures without interdisciplinary interactions). One basic condition for developing successful IPE activities in dental hygiene programs therefore has to be to consider that IPE is not merely the side-by-side education of students from different disciplines in one classroom, but that it requires meaningful interactions among these students. This study also found that large percentages of responding programs faced logistical challenges such as schedule coordination and curriculum overload. In addition, challenges related to faculty development efforts need to be addressed. IPE was clearly viewed as a priority by these program directors for themselves and the dental hygiene profession in the U.S. The importance of IPE for meeting the spirit of the CODA standards was also seen to be very high. Future research should develop IPE curricula for use as best practices to help dental hygiene programs engage in meaningful IPE and contribute to developing interprofessional care in the U.S. health care system.

\section{Acknowledgments}

This study was conducted in partial fulfillment of the Doctor of Health Science requirements of the first author. We want to thank Dr. Allan Formicola for giving us permission to use the survey developed by the ADEA Study Team on IPE and revise it for this study. We would also like to thank Dr. De Peralta for her support for this work.

\section{REFERENCES}

1. World Health Organization Department of Human Resources for Health. Framework for action on interprofessional education and collaborative practice. Geneva: World Health Organization, 2010.

2. Formicola AJ, Andrieu SC, Buchanan JA, et al. Interprofessional education in U.S. and Canadian dental schools: an ADEA team study report. J Dent Educ 2012;76(9): 1250-68.

3. Commission on Dental Accreditation. Accreditation standards for dental education programs. 2013. At: www. ada.org/ /media/CODA/Files/predoc.ashx. Accessed 17 March 2015.

4. Jones ML, Boyd LD. Interdisciplinary approach to care: the role of the dental hygienist on a pediatric feeding team. J Allied Health 2012;41(4):190-7.

5. Conway SE, Smith WJ, Truong TH, Shadid J. Interprofessional pharmacy observation activity for third-year dental students. J Dent Educ 2014;78(9):1313-8.

6. Anderson KL, Smith BS, Maseman DC. Integration of an oral health curriculum into a physician assistant program. J Allied Health 2011;40(1):19-24

7. Goldie MP. The future of the dental hygiene profession. Int J Dent Hyg 2012;10(1):1-2.

8. Wilder RS, O'Donnell JA, Barry JM, et al. Is dentistry at risk? A case for interprofessional education. J Dent Educ 2008;72(11):1231-7.

9. Commission on Dental Accreditation. Accreditation standards for dental hygiene education programs. 2013. At: www.ada.org/en/coda/current-accreditation-standards/. Accessed 17 March 2015. 
10. Nadershai NA, Bender DJ, Beck L, et al. A case study on the development of an integrated, multidisciplinary dental curriculum. J Dent Educ 2013;77(6):979-87.

11. Mattheos N, Storrs M, Foster L, Oberholzer T. Intraprofessional, team-based treatment planning for oral health students in the comprehensive care clinic. J Dent Educ 2012;76(12):1589-99.

12. Bennett PN, Gum L, Lindeman I, et al. Faculty perceptions of interprofessional education. Nurse Educ Today 2011;31:571-6.

13. Lie D, Walsh A, Segal-Gidan F, et al. Physician assistant students' views regarding interprofessional education: a focus group study. J Phys Assist Educ 2013;24(1):35-41.

14. Ateah CA, Snow W, Wener PL, et al. Stereotyping as a barrier to collaboration: does interprofessional education make a difference? Nurse Educ Today 2011;31:208-13.
15. Berwick DM, Nolan TW, Whittington J. The triple aim: care, health, and cost. Health Aff 2008;27(3):759-69.

16. Brandt B, Lutfiyya MN, King JA, Chioreso CA. Scoping review of interprofessional collaborative practice and education using the lens of the triple aim. J Interprof Care 2014;28(5):393-9.

17. Hood K, Cant R, Leech M, et al. Trying on the professional self: nursing students' perceptions of learning about roles, identity, and teamwork in an interprofessional clinical placement. Appl Nurs Res 2013:109-14.

18. Curran VR, Sharpe D, Flynn K, Button P. A longitudinal study of the effect of an interprofessional education curriculum on student satisfaction and attitudes towards interprofessional teamwork and education. J Interprof Care 2010;24(1):41-52.

19. Olson R, Bialocerkowski A. Interprofessional education in allied health: a systematic review. Med Educ 2014;48(3):236-46. 